\title{
The Ethics Gap
}

\author{
Rajiv Ahluwalia ${ }^{1}$, Ridhi Aggarwal ${ }^{2}$, Dakshina Bisht ${ }^{3}$ \\ ${ }^{1}$ Vice Dean, Professor and Head of Department \\ ${ }^{2}$ Post graduate Student \\ ${ }^{3}$ Academic Dean \\ Department of Orthodontics, Santosh Dental College, Ghaziabad, UP \\ Corresponding Author: Dakshina Bisht \\ E-mail: dakshinabisht@gmail.com
}

\begin{abstract}
Ethics involves systematizing, defending and recommending concepts of right and wrong conduct. There are various ethical codes and regulations by several councils and committees in the healthcare system, however, the ideology of bioethics in Dentistry towards implementation of bioethical principles in the treatment of patients with dentofacial anomalies is still lacking. The documents were analyzed individually by using Bardin's method of reading. Qualitative analysis of all text passages containing several bioethical references were highlighted and extracted for further analysis. Scientific publications revealing the interrelation of basic bioethical principles and characteristics relevant during treatment of patients with dentofacial anomalies were monitored and analyzed from 1975 to 2018. The study showed that an orthodontist must follow basic bioethical principles such as benevolence, autonomy, causing no harm, and justice in order to instill the patient-doctor trust and practice a healthy clinical practice. It emphasizes the need to use these principles in facing ethical issues commonly faced in clinical practice. "Ethical gap" in contemporary practice is simple means to bridge it and is the need of the hour.
\end{abstract}

Keywords: Ethics, bioethics, gap, dentistry, India.

\section{INTRODUCTION}

"Ethical gap" is the lacunae between the expected ethical conduct by a professional and his/her actual conduct in dealing with bioethical issues. According to UNESCO, Bioethics can be defined as the systematic, pluralistic and interdisciplinary study involving the theoretical and practical moral issues raised by the life sciences and humanity's relationship with the biosphere [1]. Bioethics proposes on reflecting and discussing the developments in technology and their use in favor of the human being so as to assist humanity in participating with positive awareness in the process of biological evolution and cultural development. Bioethics leads to the consideration of issues that affect not only the human being as the subject of a health treatment, but an entire society.

\section{Challenges faced in today's Dentistry includes [2]:}

- Poor knowledge and attitude towards ethics among Dental practitioners

- Poor informed consent process

- Inadequate sterilization and waste management in Dental clinics 
- Incompetence among Dental professionals

- Increase in the cost of Oral health services

- Conflict in advertising

- Clustering of Dental clinics in urban areas

- Disagreement with treatment modalities among Dentist and patient

- Poor medical record maintenance

- Requirement of consensus about the treatment procedures among dentists

As per the Dentists Regulation (Code of Ethics) 1976, revised in 2014 following are considered to be unethical practices in India: [3]

a. Employment of a dentist in his professional practice or any professional assistant (not being a registered Dental hygienist or a registered Dental mechanic) whose name is not registered in the State Dentists register, to practice dentistry as defined in clause (d) of Section 2 of the act.

b. Styling by any Dentist or a group of dentists' his/their 'Dental Clinic' or chamber/s by the name of Dental Hospital/s.

c. Signing under his name and authority any certificate that is untrue, misleading or improper, or giving false certificates.

d. Advertising, whether directly or indirectly, for the purpose of obtaining patients or obtaining his own professional advantage.

e. Employing any agent or canvasser for the purpose of obtaining patients or being associated with or employed by those who procure or sanction such employment.

f. Using of sign-board larger than 0.9 metre by 0.6 metre and the use of such words as 'Teeth', 'Painless Extraction'

g. Insertion of any paragraphs and notice in the press and also the announcement of names in the trading lists and the display of their names or announcements at places of public entertainments; other than the change of his address.

h. Using of abbreviations like (I) RDP for Registered Dental Practitioner, (ii) MIDA for Member, Indian Dental Association, (iii) FICD for Fellow of International college of Dentists, (iv) MICD for Master of International College of Dentists, (v) FACD for Fellow of American College of Dentists, (vi) MRSH for member of Royal Society of Hygiene etc. and the like which are not academic qualifications.

According to Surveys conducted in Chennai more than $65 \%$ of Dentists do not follow the above norms. However, to control Unethical Practices certain actions are prescribed by the council [3].

1. When a complaint or information is received by the State Dental council that any dentist is resorting to any unethical practice as mentioned in regulation 6 , or is committing a breach of any other of these regulations, the concerned State Dental council may call upon him to explain and after giving him a reasonable opportunity of being heard after making such enquiries, if any, as it may deem fit, decide whether such a practice tent amounts to infamous conduct in any professional respect or contravenes any of the provisions of any other of these regulations, and then determine the action to be taken against the Dentist under Section 44 of the Act.

2. As and when a complaint of breach of these regulations is brought to the notice of the Registrar of a State Dental Council, he shall take prompt action.

\section{Areas of Concern}

Quality of Care- Dentists need to provide good quality care to patients to justify the faith with which patients approach the dentist [4]. Fully documented and complete information regarding patient's treatment must be shared with the patient.

Advertising -Advertising is one such factor linked with quality of care. The primary concern is that Dentists whose marketing and advertising activities are considered unprofessional.[6] Many 
Dentists believe that aggressive marketing practices such as discount ploys are not only in bad taste but also diminish the profession in the public.

Patient Autonomy- Issues of informed consent and the need to put patient's interest first are considered very important issues [4]. Informed consent is a significant ethical challenge to the dentist because of the large number of different materials and different techniques available for the same or similar problems [4]. Patient's details should not be shared with anyone including social media. Personal details, photos, treatment given too cannot be shared. A lot of groups on social media (WhatsApp) innocently discuss patient treatment options in reference to patient photographs and records. This may be construed as an inappropriate conduct.

Split Fees in Advertising and Marketing Services - The prohibition against a Dentist's accepting or tendering rebates or split fees applies to business dealings between Dentists and any third party, not just other Dentists [5]. Thus, a Dentist who pays for advertising or marketing services by sharing a specified portion of the professional fees collected from prospective or actual patients with the vendor providing advertising or marketing services is engaged in fee splitting [5]. The prohibition against fee splitting is also applicable to marketing of Dental treatments or procedures via "social coupons" if the business arrangement between the Dentist and the concern providing the marketing services for that treatment or those procedures allows the issuing company to collect the fee from the prospective patient, retain a defined percentage or portion of the revenue collected as payment for the coupon marketing service provided to the dentist and remit to the Dentist the remainder of the amount collected [5].

Poor Knowledge and Attitude toward Ethics among Dental Practitioners: Ethics is extremely important and it differs from doctor to doctor [2]. An unbalanced knowledge of informed consent among the current dentists has suggested the need for awareness programs to fill the knowledge gaps and instill positive attitudes. To overcome this, emphasis should be given in undergraduate and postgraduate training on legal jurisprudence and legal medicine as this is essential for dentists to protect themselves from civil litigation (trespass, assault, or battery) and even criminal proceedings for common aggravated or indecent assault [6]. Increase in Cost of Oral Health Service: Rising cost of health care can limit patient access to health care, limited resources leading to rationing and delaying and denial of care to people in need. Escalating cost can lead to inverse care law [2]. Disparity in the economic status forces the budding doctors to opt for a sector where they are highly paid and thus not opting for rural service and thus making them suffer [2].

Poor Medical Record Maintenance: as the consumer negligence cases are increasing, it is important to maintain medical records [2]. Subject experts felt that "Medical Record is a legal document and reference for future cases. It safeguards the Dentists against fraud/false statements by patients which are intended to harm/defame them [2].

\section{METHODOLOGY}

The documents were analyzed individually by using Bardin's method of reading, which consists of a pre-analytical reading, exploration of the material and interpretation [7]. During the qualitative analysis, all the text passages containing bioethical reference to the principles of autonomy, beneficence and non-maleficence were highlighted and extracted for further analysis. Keywords used for search were "Ethics", "Bioethics", "Gap", "Dentistry" and "India"

\section{DISCUSSION}

Several aspects that directly influence a population's access to public Dental services and actions that contribute to inequities in oral health are questions of ethical content and should be examined from ethical standpoints, especially protection and intervention bioethics.

Health authorities are responsible for the reasonable and effective well-being of the population by ensuring access to health services and other health programs and it is their protective responsibility to control the outcome of adopted policies and the evaluation of the performance of institutions and their employees. Bioethics and values such as dignity, human rights, respect 
for autonomy and vulnerability, must be incorporated in the curriculum, taught effectively and practiced in our Dental schools. Dental schools, associations, councils must undertake the mammoth task of educating the "existing dental healthcare workers" of their bioethical obligations. Bioethics must be taught as a primary, focused and important aspect of Bachelors and Master's program. "The eyes cannot see what the mind does not know". Hence, educating the fraternity of the existing bioethical values is the best option to bridge this "ethical gap".

\section{REFERENCES}

1. ten Have $\mathrm{H}$, Jean M, editors. The UNESCO universal declaration on bioethics and human rights: Background, principles and application. UNESCO; 2009.

2. Kemparaj VM, Panchmal GS, Kadalur UG. The Top 10 ethical challenges in dental practice in Indian scenario: Dentist perspective. Contemp Clin Dentistry 2018;9(1):97-9.

3. Ahuja BS. The Revised Code of Dental Ethics. World J Adv Sci Res 2019;2:1-38.

4. Naik SP, Nivedan KS,Pinto B, Shobha R, Dutt AS, Rahul N. Ethical Issues And Challenges in Dentistry. Int J Prev Clin Dent Res 2016;3(4):285-87.

5. The ADA Principles of Ethics and Code of Conduct. American Dental Assocaition. Available from: https://www.ada.org/en/about-the-ada/principles-of-ethics-code-of-professionalconduct

6. Gupta VV, Bhat N, Asawa K, Tak M, Bapat S, Chaturvedi P. Knowledge and attitude toward informed consent among private dental practitioners in bathinda city, punjab, India. Osong Pub Health Res Persp 2015;6(2):73-8.

7. Ademir A, Alqerban A, Antonio DL, Orlando T, França B. The orthodontist's responsibility and the bioethical aspects in the current jurisprudence. Eur J Gen Dentistry 2012;1(1):20-3.

Acknowledgements - Nil

Source of Funding - Nil

Conflict of Interest - Nil 